\title{
Engineering Application with a visual aid and an experimental set up
}

\section{Dr. Nandita Biswas, Washington State University}

Dr. Nandita Biswas is a clinical Assistant Professor in the school of Mechanical and Materials Engineering (MME) at Washington State University, Pullman since 2014. Before joining MME, she taught undergraduate level classes as an instructor in the department of Mathematics at the same university for 3 years. She received her M.S. Degree in Mechanical Engineering from Washington State University, Pullman in 2007 and Ph.D. degree from the same department and same university in 2013. Her research interest includes Material behavior under Impact loading, Design and fabrication of high strain rate testing facility, Engineering Education and Engineering Design

\section{Mr. David Torick, Washington State University}

Mr. David Torick has been an Instructor in the School of Mechanical and Materials Engineering at Washington State University since 2015. He received his Bachelor of Science in Mechanical Engineering in 1996 from Kettering University and his Master's in Education from The Ohio State University in 1999. He also received a Master's degree in Civil Engineering from the University of Pittsburgh in 2007. David has experience as an engineer in the automotive industry, and most recently, before joining Washington State he was an application engineer for Hawk Ridge Systems, a SOLIDWORKS reseller. His research areas include engineering education focused on engineering graphics and design. 


\title{
Effective teaching for dimensioning and tolerancing in Mechanical Engineering Application with a visual aid and an experimental set up.
}

\begin{abstract}
:
This project addresses a pedagogical problem related to dimensioning and tolerancing of components and an innovative approach to solve that problem in a Mechanical Engineering freshman level Computer Aided Design and Visualization class. In this class, students learn how to dimension and tolerance a drawing for a part using a set of rules and standards but well dimensioned drawings require that a designer is aware of how the part will be created as well. Our students are asked to be good at dimensioning but they lack the context of how to apply dimensions. This project addresses the lack of experiences that makes it very challenging for our students to construct the knowledge and make this skill be recalled throughout their career. This project allows us to address the problems through a virtual experience. This work provides Mechanical Engineering freshman level students a real life experience of dimensioning and tolerancing in the context of machining. With machining videos that developed in this project, using proper dimensioning and tolerancing technique, students are now able to correlate the importance and significance of proper and practical dimensioning and tolerancing methods with machining on their engineering drawings. Initial assessment was done in the Spring 2019 semester and initial data found a strong correlation of the theory of dimensioning and tolerancing with actual machining in a meaningful way. Preliminary assessment concludes that these machining videos will have a positive lasting impact on how freshman level Mechanical Engineering students think in terms of providing information on their Engineering drawings.
\end{abstract}

Introduction:

In a freshman level Computer Aided design class students learn how to dimension and tolerance a drawing for a part using a set of rules and standards that one can follow from the American Society of Mechanical Engineers [1]. From the experience of teaching this class multiple times, it was observed that students usually miss the connection between dimensioning and actual manufacturing processes as a manufacturing experience is not offered until junior level. Lack of manufacturing experience makes it very challenging for our students to construct the knowledge [2] and make this skill be recalled throughout their career. Our undergraduate assessment continues to show that we are not performing well in this area. This paper allows us to address the problems through a virtual experience based around the success of MOOC's [3] and literature that emphasizes key qualities of online video content [4]. The target students in this project are freshman in Mechanical Engineering undergraduate program where Computer Aided Design and 
visualization class is their first Mechanical Engineering class. While there are significant number of literatures are available related to improvement of visualization in computer graphics or computer aided design class, teaching dimensioning in the context of manufacturing is rather limited especially for freshman level students with no exposer to machining concepts. Research related to teaching dimensioning with active learning or use of visual aids in undergraduate engineering classes are discussed in various literatures. Project based active learning was implemented in a freshman level Mechanical Engineering computer graphics class [5] in City college of New York and Borough of Manhattan Community College where students learn Engineering graphics with group projects after learning all fundamental concepts. While Geometric dimensioning is taught for documentation purposes, tolerancing concept is taught using actual machine parts by showing examples with specific machining concepts. An interactive selflearning tool for manufacturing dimensioning is developed to teach dimensioning in the context of machining for freshman level students [6]. The self-learning tool developed in this work includes videos of machining to explain the manufacturing dimensioning. But this work deals with simple part with various basic machining concepts and does not appear to deal with the concept of tolerancing.

From our CAD teaching experience over the last couple years, it is obvious that teaching with a visual aid enhance student's learning experience. For modeling a sheet metal part, we showed them a fabrication process video available online. Students expressed that this part of CAD learning made more sense as we use same parameters to model CAD parts that correlate with fabrication. But this part is only a small fraction of the course material. Dimensioning and tolerancing concepts are a very crucial concept to mechanical engineers. As we explained above, although we are teaching these concepts, students are lacking firm background on these due to lack of practical implementation on actual fabrication and manufacturing. If students can visualize and implement the concept they have learned from the lecture in the classroom, it will definitely solidify their learning process. Hands-on experience will help them to understand the concept at a deeper level. We expect students to understand the concept thoroughly and also be able to recall this information in any future class, internship, or career where they have to use this concept. Retention of knowledge is one of the prime objectives here. Enhanced teaching methods with the visual aid and practical implementation in the classroom will help students to achieve these goals. Some literature reviews included below to support our hypothesis.

Southwest Texas State University developed an experiment set up to implement GD\&T concept where students were able to use the concepts learned in their lecture. The study showed that their approach had a great impact on student's learning process and retention of the concept [7]. To make the learning effective and interesting, a group of researchers used teaching aid and laboratory experiments to introduce material properties and behavior in materials and material testing class in Civil Engineering and the methods were proven to be very useful for students [8]. Importance and effect of visual aid in engineering education highly emphasized the interdisciplinary workshop event [9]. When model building technique was integrated to a Theory of Machine class, it 
contributed a major improvement in students' learning process to understand the mechanisms and concepts of motion [10]. Studies conducted by two groups concluded that use of audio-visual aid as a classroom teaching method made the concept easier, interesting and very effective for the students [11], [12].

Dimensioning and tolerancing teaching:

In our university, the first engineering class for Mechanical Engineering students is a freshman level Computer Aided Design and Visualization class. Before entering this class, students take one math class as a pre-requisite. Concepts of dimensioning and tolerancing are introduced in the form of lectures, then students learn how to implement the concept using SolidWorks by doing tutorials and exercises. We have class standards in terms of dimensioning. Some of the rules include datum dimensioning, no redundant dimensioning, dimension a circle with diameter, dimension an arc with radius, no crossing dimensioning etc. The main goal here is to have an engineering drawing of a part which is completely defined to recreate a 3D model and also to allow manufacturing. We taught this freshman level computer aided design and visualization class for many semesters. Recently, we have also taught a senior design class for several semesters. In the senior design class in mechanical engineering, we teach students an engineering design process by doing hands on projects with an external customer. Students have to generate engineering drawings of all the parts that are included in the project. It was then, we realized, that some students lack the context of dimensioning in terms of machining. To address this, we came up with the idea of showing machining videos in the freshman level class to emphasize the importance of dimensioning in the context of manufacturing.

\section{Project outline:}

This ongoing project provided us the opportunity to give Mechanical Engineering freshman level students a real life experience of dimensioning and tolerancing in the context of machining. With machining videos using proper dimensioning and tolerancing technique, students are now able to correlate the importance and significance of proper and practical dimensioning and tolerancing methods with machining on their engineering drawings. This project was completed in 3 phases. In phase one, a simple interesting virtual mechanical system was designed using SolidWorks software as shown in figure 1 . That included designing of (a) each part, (b) interacting mechanisms among parts and (c) workability of the system including all the parts. The audience for these machining videos is freshman level students with no fabrication experience. With limited experience a great deal of effort was made to make it interesting and fairly simple. Also machining ideas of each components were carefully considered so that it is not overly complicated and easy to understand. After that, raw materials were purchased for the system and a detailed plan for machining every part was developed. In phase 2, undergraduate research assistants involved in this project machined every part using machine shops at our university, and video recorded all of their 
machining. In phase 3, they edited all the videos to make those concise. Also, they added audio of logical interpretation of dimensioning and tolerancing information when fabricating to make it suitable and adaptable for the freshman level Mechanical Engineering students. Each video file started with an engineering drawing of the part with necessary information such as proper dimension and tolerance values, then machining of the part using that engineering drawing as a reference where step by step of machining was explained by a background audio with an emphasis on the importance of proper measuring technique for the machining process.

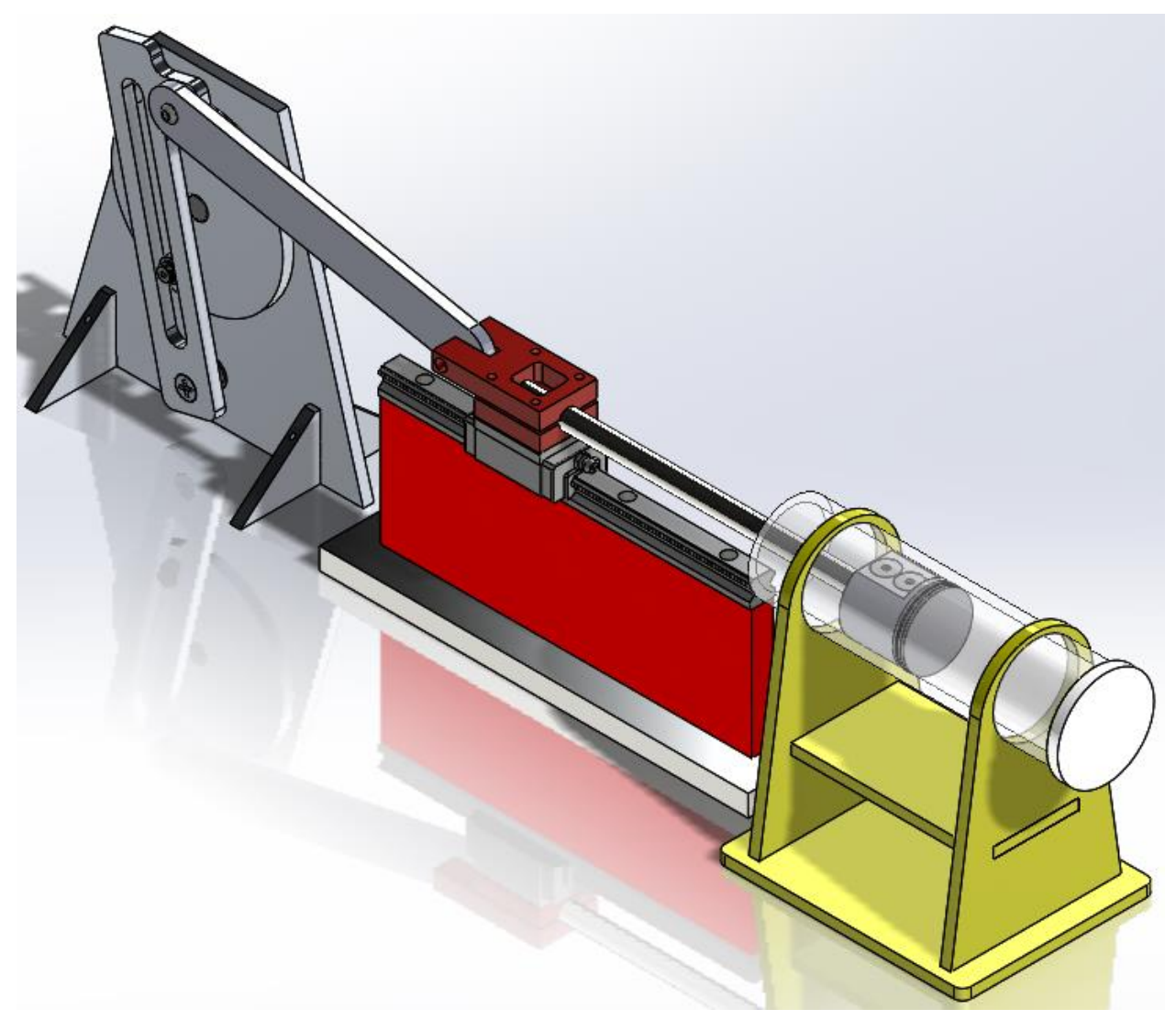

Figure 1: SolidWorks Model of experimental system

Initial assessment:

In the Spring and Fall 2019 semester, ME 116 students learned how to create engineering drawing of any part and assembly using proper dimension and tolerance values with SolidWorks tutorials and exercises. Toward the end of the semester the effectiveness of videos was assessed in 3 steps: in step 1, students were provided with a SOLIDWORKS part as shown in figure 2, from our designed mechanical system to generate engineering drawings. This is an ongoing project. Although we have multiple parts in the system shown in figure 1, only the piston shaft part in figure 2 with video was ready at the time of assessment. In step 2, fabrication video of 
the same part was then shown and students were asked to edit their drawings if they think it is necessary based on the video. In step 3, we assessed their engineering drawings before and after the machining video experience. In Spring, 2019 semester we did qualitative assessment as the video was made close to the end of semester. In Fall 2019, we assessed with the same video and result is presented in figure 3 . We had 3 sections with a total number of students in this assessment at about 72. The objective of this assessment is to check if the drawing file has enough information to machine this part. Majority of students changed their drawings after watching the machining video, and it was apparent that they were able to correlate the theory of dimensioning and tolerancing with actual machining in a meaningful way. This is an ongoing project and assessment is still in initial state. The figure 3 showed clear trend of improvement between regular dimensioning to define a part versus dimensioning for manufacturing after watching machining video where they saw how the dimension was used to make that specific part.

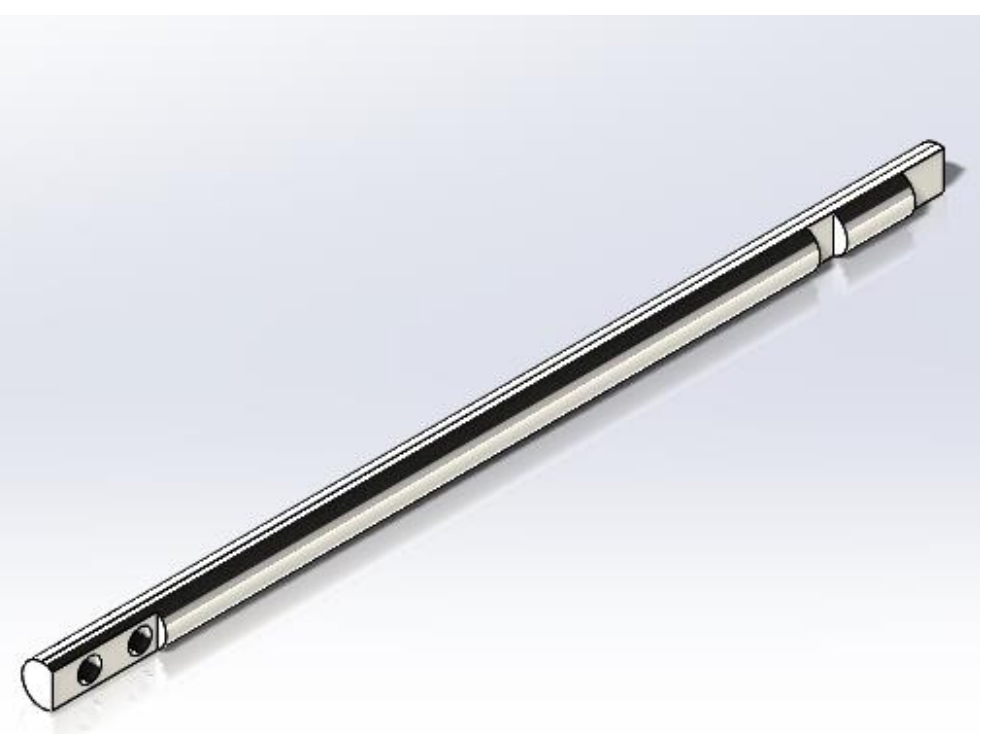

Figure 2: Piston shaft 


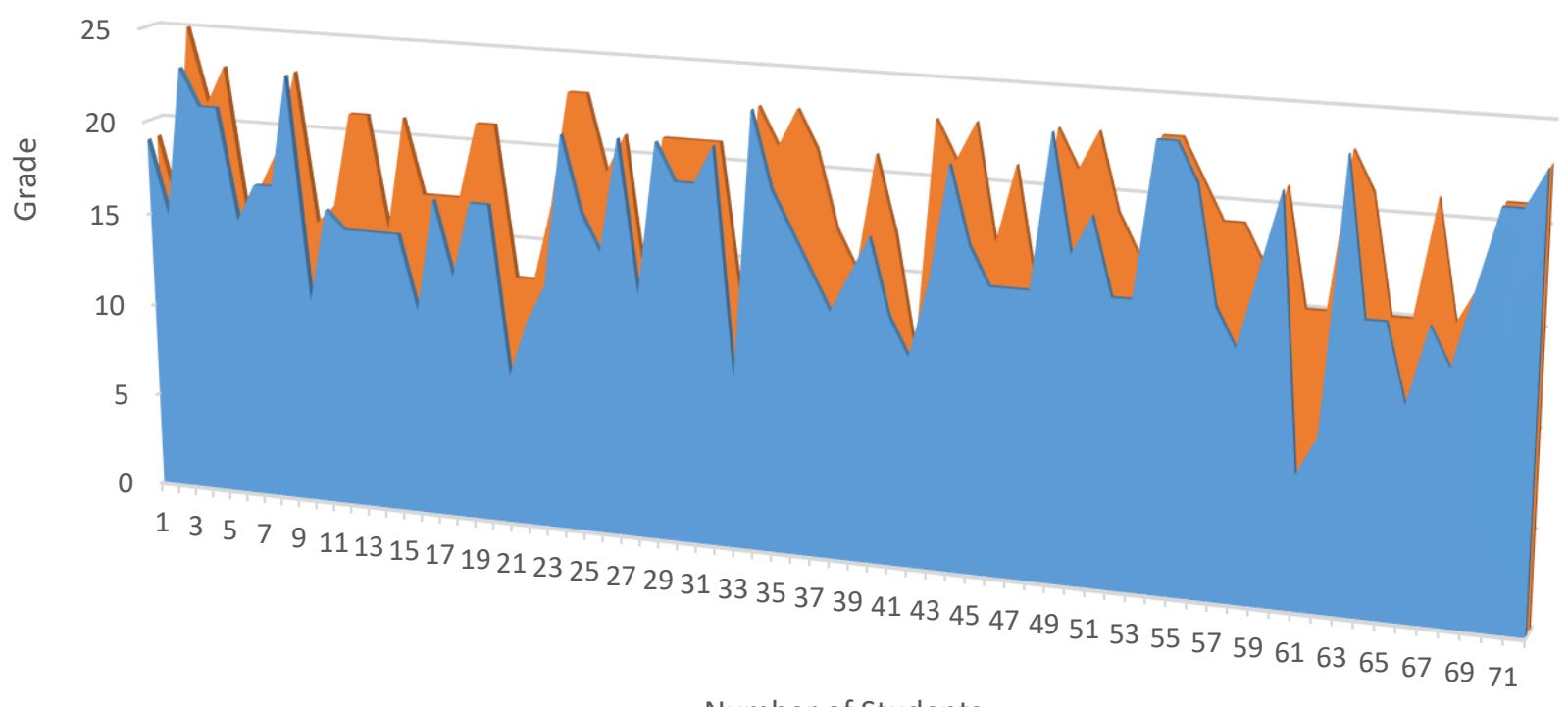

Number of Students

a Regular Dimensioning Dimensioning after video treatment

Figure 3: Comparison plot with and without video treatment

Conclusion and Future Plan:

This work is still in progress. The initial assessment results in Figure 3 showed the positive outcome. The outcome was measured against a set of dimensioning rules which is a standard for the freshman level computer aided design and manufacturing class. The goal was to achieve an engineering drawing with complete information that can be used to manufacture the part. Preliminary data is very promising and we are confident that machining videos will have a positive lasting impact on how they think in terms of providing information on their Engineering drawings. We plan to show more videos with various parts shown in figure 1 in coming semesters, gather data on the impact of active learning using these visual aids. We also plan to assess their understanding of tolerancing from the data. We plan to present highlights of our resources and the impact of these resources on student understanding to American Society of Engineering Educators through conference proceedings. A WordPress site is under development where we will share all the resources for any interested faculty member to access and use in their classroom. 
References:

[1] ASME Y14.5-2009, Dimensioning and Tolerancing: Engineering Drawings and Related Documentation Practices: An International Standard. American Society of Mechanical Engineers, New York, 2009.

[2] K. Tobin, The practice of constructivism in science education. Hillsdale, NJ: Psychology Press, 1993.

[3] B. Ferster, Teaching machines: learning from the intersection of education and technology. Baltimore, Maryland: Johns Hopkins University Press, 2014.

[4] P.J. Guo, J. Kim, R. Rubin, How video production affects student engagement: An empirical study of mooc videos, In Proceedings of the first ACM conference on Learning@ scale conference, March, 2014, pp. 41-50.

[5] M. K. Ardebili and A.M. Sadegh, A New Approach to Teaching Engineering Graphics Using Active Learning and Product Realization, American Society for Engineering Education Annual Conference \& Exposition, Salt Lake City, Utah, June 20-23, pp. 9.76.1-9.76.7, 2004.

[6] G. Baronio, B. Motyl, P. Diego, “Technical Drawing Learning Tool-Level 2: An interactive self-learning tool for teaching manufacturing dimensioning", Computer Application in Engineering Education, vol. 24, no. 4, March, 2016.

[7] V. Sriraman, J.D. Leon, "Teaching Geometric Dimensioning and Tolerancing in a Manufacturing Program”, Journal of Industrial Technology, vol. 15, no. 3, p. 2-6, May-July 1999.

[8] S. A. Durham, W. M. Hale, S. Freyne, Teaching Aids and Laboratory Experiments to Enhance Materials Learning, Proceedings of the 2007 Midwest Section Conference of the American Society for Engineering Education, Wichita, KS, Sep. 19-21, 2007.

[9] A. M. Barry, D. Berry, S. Cunningham, J. Newton, M. Schweppe, A. Spalter, W. Whiteley, R. Williams, Visual Learning for Science and Engineering. A visual Learning Campfire, Snowbird, Utah, June 1-4, 2002.

[10] G.R. Chalageri, G.U, Raju, Teaching Reform through Model building in Theory of Machine Course, Proceedings of the International Conference on Transformations in Engineering Education, ICTIEE, 2014.

[11] S. Rasul, Q. Bukhsh, S. Batool, "A study to analyze the effectiveness of audio visual aids in teaching learning process at a university level", Procedia, Social and Behavioral Sciences, vol. 28, pp.78-81, Dec.2011.

[12] A. S. J. Al-Khyyat, "The impact of Audio - Visual Aids (AVA) and Computerize Materials (CM) on University ESP students' Progress in English Language. International Journal of Education and Research, vol. 4, no. 1, pp 273-282, Jan. 2016 